\title{
Schizodeme analysis of Trypanosoma cruzi Colombian strain clones isolated from the acute phase of murine infection
}

\author{
Edson LP Camandaroba* , Eliana AG Reis, Mitermayer G Reis, Sonia G Andrade/ ${ }^{+}$
}

\begin{abstract}
Laboratório de Chagas Experimental, Auto-imunidade e Imunidade Celular, Laboratório de Patologia e Biologia Molecular, Centro de Pesquisas Gonçalo Moniz-Fiocruz, Rua Valdemar Falcão 121, 40295-001 Salvador, BA, Brasil *Laboratório de

Histologia e Embriologia Animal Comparada, Universidade Estadual de Feira de Santana, Feira de Santana, BA, Brasil
\end{abstract}

Colombian strain of Trypanosoma cruzi, biodeme Type III (T. cruzi I), has been cloned by micromanipulation at two phases of the acute infection: early (10 days) and advanced (30 days). Twelve clones were obtained therefrom. Characterization by their biological and biochemical behavior showed an identity among the several clones and their parental strain, albeit with different degrees of virulence. Molecular characterization of the kinetoplast DNA $(k D N A)$ after amplification by polymerase chain reaction revealed identical profiles of the bands from the kDNA minicircle by the analysis of restriction fragment lenght polymorphism for the isolated clones, their parental strain, and to the clones isolated at two different phases of the infection. Results suggest the predominance of a "principal clone", in the composition of the Colombian strain, responsible for the biological and biochemical behavior. However, no relationship was detected between the molecular profile of kDNA and the degree of virulence presented by the several clones.

Key words: Trypanosoma cruzi - Colombian strain clones - schizodeme

Molecular characterization of strains and clones of Trypanosoma cruzi was first performed by Morel et al. (1980), through electrophoretic separation of restriction endonuclease-generated fragments of the kinetoplast DNA, by the restriction fragment length polymorphism technique (RFLP), in order to obtain the electrophoretic profiles or schizodeme, also known as "restriction fingerprints" (Morel et al. 1986). The polymerase chain reaction (PCR) can be used to amplify the fragments of kDNA minicircles of T. cruzi, allowing its direct detection and genotype classification (Avila et al. 1990). Studies on the clonal composition of several strain maintained for prolonged time in laboratory have allowed the identification of either strains with an homogeneous clonal structure or the presence of heterogeneous clones, as has been demonstrated for the Y and CL strains (Deane et al. 1984, Morel et al. 1986). Previous studies have demonstrated a clonal homogeneity for the $21 \mathrm{SF}$ strain (T. cruzi II), prototype of Biodeme Type II (Andrade \& Magalhães 1997), by both the biological and isoenzymic characterization (Campos \& Andrade 1996), corresponding to a high degree of similarity by RFLP analysis for characterization of kDNA (Campos et al. 1999). Clones isolated from the Colombian strain, representing the Type III Biodeme (T. cruzi I), also demonstrated similarity among them (Camandaroba et al. 2001). However, they presented variable degrees of virulence, regardless of their main biological characters, and isoenzyme profiles. The hypothesis that the several clones, isolated either from the early or advanced phases of acute infection, could differ in their molecular structure of the

\footnotetext{
${ }^{+}$Corresponding author: sgandrade@cpqgm.fiocruz.br Received 25 January 2006

Accepted 19 July 2006
}

kDNA is investigated in the present study by the molecular characterization of its clones at the level of kDNA variable portions of the minicircles, to further clarify the relationship between the parasite biological behavior and its clonal structure (Andrade 1999).

\section{MATERIALS AND METHODS}

Parental strains and clones of T. cruzi strains - Seven clones of the Colombian strain, isolated at the 30th day of infection ( $C 1, C 2, C 3, C 4, C 5, C 6, C 7)$, and five clones isolated at the 10th day of infection $(C 8, C 10, C 13, C 14$, C15), were obtained by micromanipulation (Dvorak 1985), by isolating one single parasite from citrated mouse blood; after centrifugation at $900 \mathrm{~g}$, the supernatant was examined in a Neubauer chamber for evaluation of parasite concentration, diluted with PBS, $\mathrm{pH} 7.2$, and drops of $1 \mu 1$ were distributed in the wells of titration plaques and examined on an inverted microscope. By means of micromanipulation a single trypomastigote form, isolated with 1 $\mathrm{ml}$ syringe was inoculated into one 8-day-old mouse. Clones and parental strains were inoculated into groups of mice for biological characterization: evolution of parasitemia, cumulative mortality and isoenzymic profiles of parasites. Clones isolated either at the 30th or 10th day of infection varied in virulence, as evaluated by the levels of parasitemia and mortality, as follows: (1) seven clones isolated at the 30th day of infection: high virulence - clones C1, C3, C4 , C6; low virulence - clones C2, C5,C7; (2) five clones isolated at the 10th day of infection: high virulence - clones C13, C14; low virulence - clones C8, C10, C15. The parental strain $(\mathrm{Col}-\mathrm{P})$, disclosed high virulence.

Molecular characterization by the schizodeme analysis - Isolation of total kDNA from the parental Colombian strain ant its clones was obtained from axenic culture, using the Genomic kit $\left(\mathrm{GFX}^{\mathrm{tm}}\right)$ from Pharmacia. Parasites were cryopreserved and $100 \mu \mathrm{l}$ were transferred to a filtra- 
tion column connected to an Eppendorf tube added with $34 \mathrm{ml}$ of lysis buffer plus $134 \mu \mathrm{l}$ of extraction buffer. The samples were washed with lysis and extraction buffers, centrifuged with Wash solution (Pharmacia) followed by addition of $50 \mu \mathrm{l}$ of ultra-pure and sterile water at $70^{\circ} \mathrm{C}$. After centrifugation at $9000 \mathrm{rpm}$, the samples were maintained in cold chamber until use.

Amplification by PCR of kDNA minicircles variable regions - Was performed in $100 \mu \mathrm{l}$ reaction mixture containing $10 \mathrm{mM}$ Tris $\mathrm{HCl}(\mathrm{pH} 8.4), 50 \mathrm{mM} \mathrm{KCl}, 2.0 \mathrm{mM}$ $\mathrm{MgCl}_{2}, 200 \mu \mathrm{M}$ of each dNTP, $2 \mu \mathrm{lDNA}(\sim=0.5 \mu \mathrm{g}), 2.5 \mathrm{U}$ of Taq polymerase (Perkin Elmer-Cetus Corporation) 2 pmols of previously described oligonucleotide primers 35 and 36 to amplify fragments of $330 \mathrm{bp}$. After an initial 5 min denaturation step at $94^{\circ} \mathrm{C}, 35$ cycles of amplification were performed on DNA thermal cycler (Perkin Elmer-Cetus gene Amp PCR System 9600) with a step program consisting of $45 \mathrm{~s}$. Denaturation at $94^{\circ} \mathrm{C}, 45 \mathrm{~s}$ annealing at $55^{\circ} \mathrm{C}$ and $1 \mathrm{~min}$ extension at $72^{\circ} \mathrm{C}$. Additional $10 \mathrm{~min}$ extension step at $72^{\circ} \mathrm{C}$ was performed at the end of reaction. Each PCR round had a negative control (ultra-pure water) and normal serum of human patient. In order to confirm the results, PCR products of the predicted size ( $330 \mathrm{bp})$ were separated by electrophoresis in a $2 \%$ agarose gel.

kDNA analysis was performed by comparative study of the RFLP obtained from the digestion of amplified minicircle kDNA variable region by $R s a \mathrm{I}, \operatorname{Hinf} \mathrm{I}$, and $E c o$ $R \mathrm{I}$ restriction endonucleases, according to the manufacturer's procedures (Pharmacia Biotech). The kDNA fragments were separated by electrophoresis in a 7\% polyacrylamide gel on the system electrophoresis vertical (Pharmacia), ethidium bromide stained (Pharmacia), and visualization in the system Eagle eye I.

\section{RESULTS}

PCR amplification of the 12 clones revealed the presence of $330 \mathrm{bp}$ fragments from the k-DNA amplified minicircles of every clone as shown in Fig. 1A. The bands' profiles of the restriction fragments from the minicircles of kDNA (RFLP) are shown in the Figs B, C, and D. They were identical for all the clones, as compared with the parental strain and the clones isolated at two different phases of infection.

\section{DISCUSSION}

The clonal structure of T. cruzi strains has been proposed by Tibayrenc et al. (1986) which postulated that T. cruzi strains are natural clones and the natural selection, favoring only certain genetic patterns of combinations, could account for a limited number of isoenzyme strains, which are represented by three major clones. Results from the present study confirmed the clonal homogeneity of the Colombian parental strain and their 12 clones, which were previously detected by biological and biochemical analysis, presented the same schizodeme, indicating the predominance of a principal clone. Despite the similarity of the molecular profiles of the isolated clones, a variation in the degree of virulence between them has been registered, not only for the clones isolated at the 30th day of infection, but also for those being isolated at the 10th day.
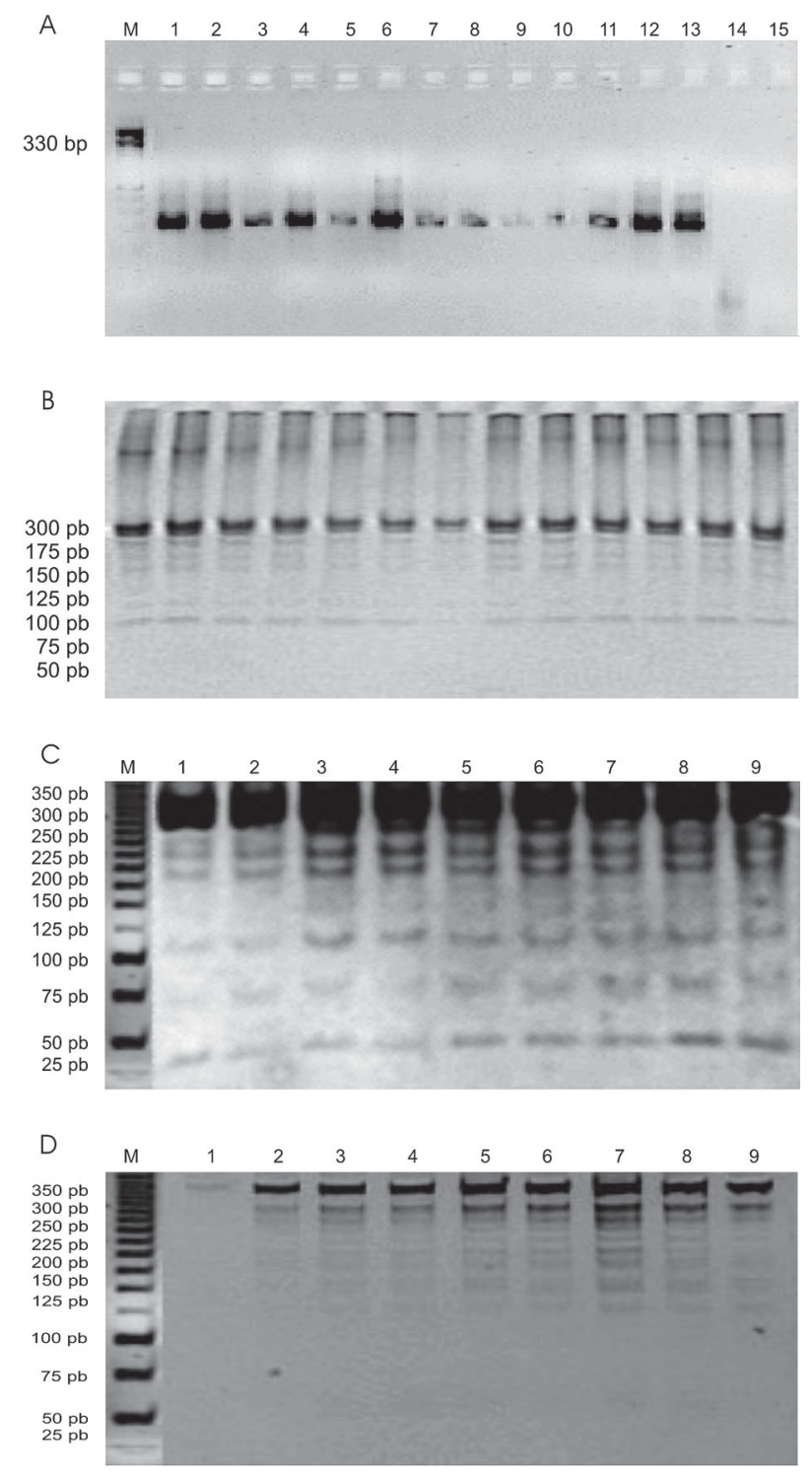

Fig. 1-A: polymerase chain reaction (PCR) amplification - M: ladder mark, 1: $C 1,2: C 2,3: C 3,4: C 4,5: C 5,6: C 6,7: C 7,8: C 8,9$ : C10, 10: $C 13,11: C 14,12: C 15,13$ : Colombian strain, 14: negative control (normal human serum), 15: negative control (water ultra pure); B: schizodeme patterns digest by Hinf I restriction enzyme - 1: Colombian strain, 2: $C 1,3: C 2,4: C 3,5: C 4,6: C 5,7$ : C6, 8: $C 7,9: C 8,10: C 10,11: C 13,12: C 14,13: C 15$; C: schizodeme patterns digest by Hinf I restriction enzyme - M: ladder mark, 1: Colombian strain, 2: $C 1,3: C 2,4: C 3,5: C 4,6: C 8,7: C 10,8: C 13$, 9: C14; D: schizodeme patterns digest by Rsa I restriction enzyme - M: ladder mark, 1: Colombian strain, 2: $C 2,3: C 3,4: C 4,5: C 5,6$ : C8, 7: C7, 8: C10, 9: C13.

These results seem to indicate that the character of virulence does not depend on kDNA structure. Using other molecular methods (MLEE and RAPD), Revollo et al. (1998) confirmed a correlation between the genotype characteristics and phylogenetic variability of T. cruzi. Other evidences indicate that the virulence of strains and clones are correlated with the nuclear DNA, as has been demonstrated by Espinoza et al. (1998), through genetic 
analysis by Southern blot of total DNA. They showed that the DNA hybridized with a repetitive element from the rRNA gene spacer for five strains isolated from patients in Mexico, and therefore could distinguish two strains with low virulence from three with high virulence.

The possibility to explore these molecular tools in the investigation of the genotype characteristics of 12 clones from the Colombian strain, regarding their respective degrees of virulence, represents new perspectives for future studies.

\section{REFERENCES}

Andrade SG 1999. Trypanosoma cruzi: clonal structure of parasite strains and the importance of principal clones. Mem Inst Oswaldo Cruz 94 (Suppl. 1): 185-187.

Andrade SG, Magalhães JB 1997. Biodemes and zymodemes of Trypanosoma cruzi strains: correlations with clinical data and experimental pathology. Rev Soc Bras Med Trop 30: 27-35.

Avila H, Gonçalves AM, Nehme NS, Morel CM, Simpson L 1990. Schizodeme analysis of Trypanosoma cruzi stocks from South and Central America by analysis of PCR-amplified minicircle variable region sequences. Mol Biochem Parasitol 42: 175-188.

Camandaroba ELP, Campos RF, Magalhães JB, Andrade SG 2001. Clonal structure of Trypanosoma cruzi Colombian strain (biodeme Type III): biological, isoenzymic and histopathological analysis of seven isolated clones. Rev Soc Bras Med Trop 34: 151-157.

Campos RF, Andrade SG 1996 Characterization of subpopulations (clones and subclones) of the 21 SF strain of Trypanosoma cruzi after long lasting maintenance in the laboratory. Mem Inst Oswaldo Cruz 91: 795-800.

Campos RF, Gonçalves MS, Reis EAG, Reis MG, Andrade SG 1999. Comparative analysis by polymerase chain reation amplified minicircles of kinetoplast DNA of a stable strain of Trypanosoma cruzi from São Felipe, Bahia, its clones and subclones: possibility of predominance of a principal clone in this area. Mem Inst Oswaldo Cruz 94: 23-29.

Deane M, Sousa M, Pereira N, Gonçalves A, Momen H, Morel C 1984. Trypanosoma cruzi: inoculation schedules and reisolation methods select individual strains from doubly infected mice as demonstrated by schizodeme and zymodeme analyses. J Protozool 31: 276-280.

Dvorak JA 1985 Single cell isolates of Trypanosoma cruzi: how an why? Rev Soc Bras Med Trop 18 (Supl.): 28-38.

Espinoza B, Vera-Cruz JM, González H, Ortega E, Hernández R 1998 Genotype and virulence correlation with Mexican stocks of Trypanosoma cruzi isolated from patients. Acta Trop 70: 63-72.

Morel C, Chiari E, Plessmann Camargo E, Mattei DM, Romanha AJ, Simpson L 1980. Strains and clones of Trypanosoma cruzi can be characterized by pattern of restriction endonuclease products of kinetoplast DNA minicircles. Proc Natl Acad Sci USA 77: 6810-6814.

Morel CM, Deane MP, Gonçalves AM 1986. The complexity of Trypanosoma cruzi populations revealed by schizodeme analysis. Parasitol Today 2: 97-101.

Revollo S, Oury B, LaurenT J, Barnabé C, Quesney V, Carrière B, Noël S Tibayrenc M 1998. Trypanosoma cruzi: impact of clonal evolution of the parasite on its biological and medical properties. Exp Parasitol 89: 30-39.

Souto RP, Fernandes O, Macedo AM, Campbel, DA, Zingales B 1996. DNA markers define two major phylogenetic lineages of Trypanosoma cruzi. Mol Biochem Parasitol 83: 141-152.

Tibayrenc M, Ward P, Moya A, Ayala FJ 1986. Natural populations of Trypanosoma cruzi, the agent of Chagas disease, have a complex multiclonal structure. Proc Natl Acad Sci USA 83: 115-119. 
